\title{
Shared Features of Successful Interorganizational Collaboration to Promote Local Talent Development Environments in Denmark
}

\section{Ole Winthereik Mathorne, Natalia Stambulova ${ }^{2}$, Rob Book ${ }^{1}$, Louise Kamuk Storm ${ }^{1}$, Kristoffer Henriksen 1}

${ }^{1}$ Department of Sport Science and Clinical Biomechanics, University of Southern Denmark, Odense, Denmark, ${ }^{2}$ Centre of Research on Welfare, Health and Sport, Halmstad University, Halmstad, Sweden.

\begin{abstract}
The aim of this study was to explore 11 case examples of successful talent development collaborations between sport federations, municipalities, and local clubs in Denmark in order to identify potential shared features of successful collaborations. We hypothesized that each case example would be unique, but that they would also share features that could be organized to provide practitioners with a model to guide the improvement of their practice. Grounded in the holistic ecological approach, the study was designed as a multiple case study to facilitate a cross-case analysis. Three Danish sport federations (handball, ice hockey, and swimming), nine municipalities, and eleven local clubs participated in the study, and the data was generated from 23 semi-structured interviews with stakeholders. Analysis led to the construction of six shared features of successful interorganizational collaboration organized into: (1) a list of features (SFIC-TD) with positive and opposite pole descriptors and three categories: collaborative philosophy, collaborative decisions, and collaborative actions, and (2) an applied framework termed the pyramid model for optimization of interorganizational collaboration in talent development (PIC-TD) which illustrates how the abovementioned categories lead to collaborative outcomes. Developing a shared philosophy of talent development was found to be a foundational starting point for successful collaboration between relevant organizations on the micro- and macro-level to improve the local athletic talent development environment.
\end{abstract}

Keywords: talent development, holistic ecological approach, organizational triangle, micro-and macro-environment

\section{Introduction}

'World-class talent development is crucial for the success of Danish elite sports. Municipalities, federations, and clubs are the key players in co-creating the ideal environments where prospective athletes can compete at the highest international senior level' (Lone Hansen, CEO of Team Denmark, retrieved 2020).

The above quote portrays the cornerstone of Denmark's athletic talent development strategy that sporting success is dependent upon the development of successful environments through collaboration of vested stakeholders. With a relatively small population of approximately six million people, Denmark must make the most of their human resources in order to maintain a high level within the global sporting arms race (Storm et al., 2016). Accordingly, Team Denmark's talent development strategy has evolved over the last decade to focus on the facilitation of athletic talent development environments (ATDE; Team Denmark, 2016) as opposed to the talent identification approach used by larger countries (Pankhurst \& Collins, 2013), and the results have been promising. For example, Denmark had a successful Olympics in 2016 amassing 15 medals, and a recent annual evaluation reported that Denmark continues to maintain high performance standards at the international level (Storm \& Nielsen, 2020). However, there remains a limited understanding of how organizations involved in athlete talent development operate and collaborate to co-create optimal ATDEs (Mathorne et al., 2020; Bjørndal et al., 2017). This multiple case study of 11 successful partnerships in Danish sports provides insights into the process and outcomes of interorganizational collaboration in talent development within a real-world context.

Interorganizational Collaboration in Sport: Previous Research

Some studies have shed light on interorganizational collaboration (IC) in sport (Babiak et al., 2018). Generally, this literature reveals that the most successful IC operate efficiently, leading to increased funds, upgraded facilities, and enhanced sponsorship revenue (Babiak \& Thibault, 2009; Frisby et al., 2004; Misener \& Doherty, 2012; Parent \& Harvey, 2009). Further, Sotiriadou et al (2017) elucidated how collaboration between the Flandern tennis federation and local tennis clubs turned into efficiencies in athlete development (e.g., player development programs, improved coaching knowledge), and the authors emphasized that talent development in local clubs can be improved through tailoring federations' support to the local clubs' needs and 
capacity. However, literature concerning how IC influences talent development day-to-day activities is sparse (Babiak \& Willem, 2017; Mathorne et al., 2020; Sotiriadou et al., 2017).

Several studies have sought to unfold the how's of IC where collaborative competencies (e.g., interpersonal understanding, teamwork, cooperation, etc.) and coordination enhancing factors have been acknowledged as essential for efficient collaboration (e.g., Babiak \& Willem, 2017). Misener and Doherty (2012) identified relationship quality attributes including engagement, balance (e.g., a two-way give and take approach), consistency, and trust; they also highlighted as imperative the collaborative skills, such as interpersonal (e.g., communication), conceptual (e.g., planning and decision making), and technical (e.g., coaching, fundraising). In their literature review on IC in sport management, Babiak and Willem (2017) suggested the following key factors for coordination of ICs: enforceable and public engagements of the partners, clear objectives, explicating procedures and agreements, collective responsibility for the outcomes, defining clear roles, and appointing a manager responsible for the collaboration. Further, they highlighted the importance of defining rules of decision making to avoid paralyzing the collaboration into a deadlock and taking into account the context of IC (Babiak \& Willem, 2017).

\section{Theoretical Underpinning}

The present study is grounded in the holistic ecological approach (HEA) to athletic talent development (Henriksen et al., 2010a; Henriksen \& Stambulova, 2017), which focuses on the whole environment around a prospective athlete, advocating that although individual factors (e.g., biological and psychological) are important, they cannot stand-alone. The HEA, which was inspired by influential frameworks developed in ecological and organizational psychology (Bronfenbrenner, 1979; Schein, 1992) suggests that successful talent development is contingent upon the integrated efforts of various stakeholders from both athletic and non-athletic domains and across various levels of an ATDE (i.e., micro and macro). While the HEA has contributed to the understanding of an environment's influence within athletic talent development, there is a need to better understand how organizations across these various levels and domains operate together.

Using the HEA as a guide, our recent study (Mathorne et al., 2020) illustrated how a national sport federation, a municipality, and a club collaborated to promote talent development within the local ATDE. To our knowledge, this study was the first to investigate how collaboration between stakeholders at the macro- and micro-levels influenced management of the athletes' day-to-day activities. Two major contributions of this previous study (Mathorne et al., 2020) are worth mentioning because both were used in the present study. First, we introduced the concept of an organizational triangle, which can be defined as a collaborative relationship between three core components (e.g., federation, municipality, local club; See table 1 ) in a national talent development system operating to promote talent development within a local ATDE. All 11 cases involved in this study are organizational triangles. Second, the collaboration success factors (CSF) model (derived from elaborations on the ESF model; Henriksen et al., 2010a, see Figure 1) outlines a set of factors, including preconditions (e.g., financial, human, facilities, time), processes (e.g., strategic planning, communication, evaluation), a shared philosophy of talent development, dealing with potential conflicts, and joint initiatives and projects, which are interrelated and interact to promote collaborative success in improving the local ATDE. This

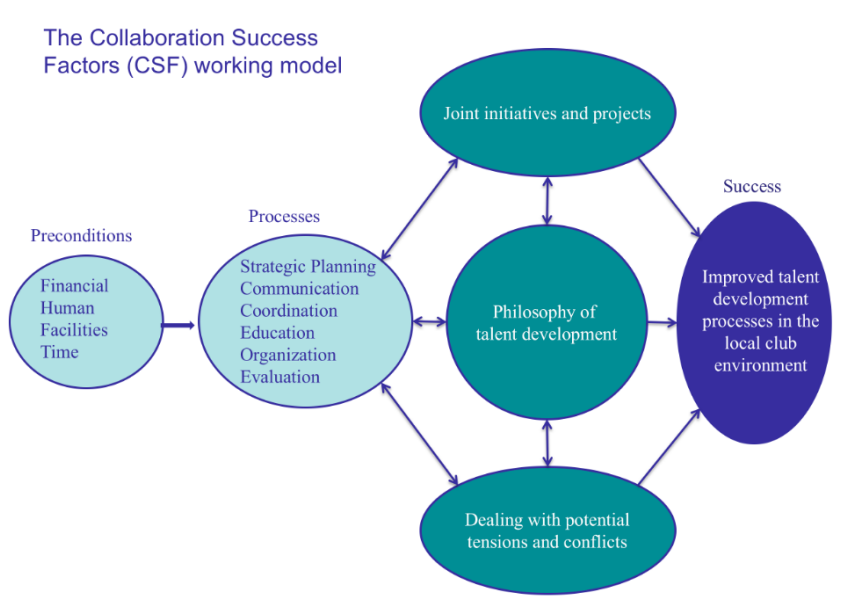

Figure 1: The collaboration success factors model

model was used in the present study as a basis for the interview guides and case descriptions.

\section{The Danish Sport System Context and Aim of the Study}

The Danish elite sport system is broadly managed by two sets of umbrella organizations that mediate development in the 98 geographical municipalities and local sport clubs. Team Denmark is a government-funded and regulated organization in charge of improving Denmark's sporting performance in a socially responsible manner (i.e., taking care of the sport and non-sport development of athletes; Skrubbeltrang et al., 2020). The Danish National Olympic Committee (DNOC) leads all national sport federations (hereafter federations). Team Denmark and the DNOC set the overall vision for talent development, provide general guidelines for age-specific training principles (Team Denmark, 2016), and distribute resources (e.g., finances, expert help) to the federations based upon their potential and past accomplishments. Local clubs have a split role of promoting overall recreational sport participation while simultaneously offering elite sport programs. Finally, the municipalities are in the strategic position of coordinating the efforts between the national and local levels (i.e., dual career initiatives; Mathorne et al., 2020). Accordingly, the decentralized structure (see Andersen et al., 2015) and a multiplicity of agents present a challenge to integrating efforts and forming a holistic approach to talent development. Consequently, within the last decade Team Denmark and federations have increasingly highlighted the role of the local ATDEs and (interorganizational) collaboration in their strategic documents. Considering the above, the aim of this study was to explore 11 case examples of successful talent development collaborations between sport federations, municipalities, and local clubs in Denmark in order to identify potential shared features of successful collaborations. We hypothesized that each case example would be unique but that they would also share features that could be organized to provide practitioners with a model to guide the improvement of their practice.

\section{Method}

Design: Multiple Case Study

The present study was a part of a project developed in collaboration between Team Denmark, municipalities, and the research team with the objective to understand successful IC within the Danish talent development system. In our first study (Mathorne et al., 2020), we investigated one successful case of IC in order to pilot the organizational 
triangle concept and CSF model. The current study was designed as a multiple case study (Stake, 2005) to compare and contrast the phenomenon of IC across 11 (case) examples. Multiple cases offer both wider and deeper understanding of the processes and the outcomes related to the topic under investigation (i.e., IC; Miles et al., 2014) than any single case. Case selection was based on the expert opinions of talent development coordinators (hereafter TDC) from three Danish sport federations (handball, ice hockey, and swimming) that were asked to provide examples of successful collaborations between the federation, the municipality, and the local club, and they provided 11 such examples (handball $=5$, ice hockey $=2$, swimming $=4$ ). We created snapshot descriptions (see Table 1) of each case using the organizational triangle concept and CSF-model as code-frames (more detailed descriptions can be found in Mathorne \& Henriksen, 2019). Further, following cross-case analysis recommendations (Miles et al., 2014; Stake, 2005) we explored features of IC across the 11 cases acknowledging their differences but focusing more on their similarities to be able to organize features of successful collaborations. The outcomes of the data analysis were: the list of shared features of successful interorganizational collaboration in talent development (SFIC-TD; Table 2) and the pyramid model for optimization of interorganizational collaboration in talent development (PIC-TD; Figure 2) seen as an applied framework.

\section{Organizations Involved in the Study and the 11 Cases}

The Danish handball federation has around 105,000 members, 777 clubs, and has been among the world's best in both female and male handball over the last several decades. The Danish handball federation has prioritized IC for some years, including a recently created full-time position focused primarily on collaboration and local talent development. The Danish swimming federation has around 200,000 members across 298 clubs, the majority of which are recreational youth swimmers (i.e., learn to swim, swim for fun). The Danish swimming federation is one of the most accomplished federations in Danish sport as well as being one of the first federations to actively promote IC between municipalities and clubs. The Danish ice hockey federation with around 5000 members and 17 clubs is a small federation. However, evolving to the men's A-level in 2002 (e.g., highest level of national teams), the federation is acknowledged for its ability to make the most of its resources by maximizing collaborative efforts with municipalities and clubs.

The municipalities in this study were located all over Denmark and covered both large and small municipalities (i.e., inhabitants between 50,000-200,000). They were all elite sport municipalities meaning that they were contractually bound to collaborate with Team Denmark to promote talent development. Each municipality had at least one Municipality-TDC employed full-time who was responsible for elite sport and talent development, and the Municipality-TDCs in this study had between 4-13 years of experience in their positions. The local clubs involved in this study differed considerably, from swimming clubs with 2000 members and full-time employees to handball clubs with 200 members and managed by volunteers, which often is the case. Some local clubs had both elite sport and grassroot participation, while others operated without a senior elite team in the club. Demographically, the participants across all three organizations consisted of 4 females and 19 males and varied considerably in age span, educational level, and years of experience.

\section{Data Collection}

The study adhered to all national ethical guidelines and was approved by the university's local department of data management. All participants were contacted by phone and e-mail to provide information about the purpose of study and ethical issues (i.e., hidden identity, the right to withdraw from the study, data to be used only for the research purpose). The issue of hidden identity was discussed thoroughly, and the participants were informed that cultural insiders and sport experts might recognize them, so full anonymity might be not reached. Seemingly it did not bother the participants, and all verbally agreed on the terms.

Data were gathered through semi-structured interviews and the analysis of documents related to the collaboration and organizations involved. Twenty-three interviews (Federation-TDCs $=3$, Municipality-TDCs $=9$ and Club-TDCs $=11$ ) were carried out using three interview guides, each created specifically for each type of organization. The interview guides were inspired by the concept of the organizational triangle and the CSF working model and divided into four sections: (1) the participants' overall perception of the collaboration (e.g., how would you describe this collaboration?); (2) descriptions of joint initiatives, projects, vital preconditions, and processes to accomplish these (e.g., please, tell me about joint initiatives or projects within this collaboration?); (3) perceived conflicts and tensions and their strategies to deal with those (e.g., how did you solve issues or conflicts within this collaboration?); and (4) overall reflections on the role of IC in talent development (e.g., what do you think will be keys to successful collaboration in the future?). The interviews lasted between 54 and 142 minutes $(M=84)$. This variation in length was caused by the number of cases they represented. For example, the Federation-TDCs from Danish handball were interviewed about five cases which led to a longer interview compared to Club-TDCs who only represented one case with their local club involved.

\section{Data Analysis}

The cross-case analysis (deductive/inductive) followed a post-positivist ("small q") version of the thematic analysis (Braun \& Clarke, 2019) and was conducted through a rigorous seven step process in order to infer the features of successful collaboration. First, inspired by the initial step in many qualitative analytical approaches (e.g., Braun \& Clarke 2019; Smith, 2016), the interview recordings were listened to, transcribed, and read repeatedly by the first author to become familiar with the data. Second, initial analysis by the first author of all 11 cases began deductively by using the CSF-model to categorize the data. At this step the amount of data was overwhelming, so the intent was to use the CSF-model as an "a coding frame" (Braun \& Clarke, 2019, p. 594) to facilitate our initial data understanding and structuring. Third, the first author presented the 11 cases in a chart to the other authors several times creating an iterative process of presenting, questioning, two-way feedback, and adjusting of the case descriptions. Such iterations were carried out until the research team became familiar with all the cases. Fourth, we worked on developing themes inductively having them in mind as features including both a positive descriptor and an opposite pole of each feature. The opposite poles were constructed as hypothetical examples, based on the research team's experiences of working with collaborations and partnerships, and derived from empirical examples provided by the study participants. Preliminary analysis produced a list of 17 themes or features, but through several rounds of feedback and reflections, the final list of 


\begin{tabular}{|c|c|c|}
\hline Case Title & Collaboration Partners and Context & $\begin{array}{l}\text { Preconditions, Processes, Philosophy, and } \\
\text { Outcomes of the Collaboration }\end{array}$ \\
\hline Swim North/ DC-SC & $\begin{array}{l}\text { Club: Large club. A full time TDC. } \\
\text { Federation: Strategy to support local ATDEs. } \\
\text { One full time TDC. } \\
\text { Municipality: Strategy to support local clubs' } \\
\text { TD efforts. One full time TDC. } \\
\text { Formal agreements: A partnership contract } \\
\text { containing their vision and action plan. } \\
\text { Issues to solve: Limited training facilities and } \\
\text { a need to promote a healthy balance between } \\
\text { school and sport. }\end{array}$ & $\begin{array}{l}\text { Collaborating TD coordinators are full-time employees } \\
\text { and can decide on their priorities and time allocation. } \\
\text { Ongoing meetings allow for efficient coordinated efforts. } \\
\text { Arranged meetings with the swimmers two times a year } \\
\text { focusing on their well-being and development. } \\
\text { Shared assumptions: Dual career balance; long-term } \\
\text { development; the whole local ATDE is important. } \\
\text { Outcomes: Was 'measured' in terms of a well- } \\
\text { functioning local ATDE; and integrations of efforts } \\
\text { between school, club and support functions (E.g., } \\
\text { physiotherapists). }\end{array}$ \\
\hline Swim West / Merge-SC & $\begin{array}{l}\text { Club: Large club. TDC is a volunteer board } \\
\text { member } \\
\text { Federation: Strategy to support local ATDEs. } \\
\text { One full time TDC. } \\
\text { Municipality: Strategy to support well-being in } \\
\text { local clubs' TD efforts. Two full time TDCs. } \\
\text { Formal agreements: A partnership contract } \\
\text { containing their vision but yet, no action plan. } \\
\text { Issues to solve: Developing a TD strategy to } \\
\text { the club and fulfill the club and municipality's } \\
\text { potential. }\end{array}$ & $\begin{array}{l}\text { All the TDCs knew one another well. The federation saw } \\
\text { an untapped potential in the ATDE and municipality and } \\
\text { thus prioritized time and resources to the ATDE. } \\
\text { Quarterly meetings with all three TDCs to support the } \\
\text { ATDE during the merge. Further, they hired a consultant } \\
\text { to guide the new club in developing a strategy. } \\
\text { Shared assumptions: long-term efforts; well-being and } \\
\text { sporting development are each other's precondition. } \\
\text { Outcomes: A well-established mutual partnership- } \\
\text { contract; increased the members from } 2200 \text { to } 2500 \text { in } \\
\text { the new club. }\end{array}$ \\
\hline Swim South & $\begin{array}{l}\text { Club: Large club. A full time TDC. } \\
\text { Federation: Strategy to support local ATDEs } \\
\text { by providing guidelines of TD to the club. One } \\
\text { full time TDC. } \\
\text { Municipality: Strategy to support the local } \\
\text { ATDE's and the athletes in sport school. Two } \\
\text { full time TDCs. } \\
\text { Formal agreements: A partnership contract } \\
\text { containing their vision and action plan. } \\
\text { Issues to solve: ATDE needed physical } \\
\text { training guidelines and plans to avoid injuries. }\end{array}$ & $\begin{array}{l}\text { The F-TDC knew the C-TDC well and knew that M-TDC } \\
\text { worked strategically and structured. } \\
\text { Quarterly meetings and ongoing communication helped } \\
\text { them to follow through plans. Developed physical } \\
\text { training guidelines; arranged meetings swimmers about } \\
\text { their well-being and development; and facilitated } \\
\text { collaboration between coaches inside the ATDE and with } \\
\text { the neighboring club. } \\
\text { Shared assumptions: Long-term efforts; well-being is } \\
\text { key; and collaboration is crucial for optimizing TD in the } \\
\text { club. } \\
\text { Outcomes: A well-established mutual partnership- } \\
\text { contract; collaboration with neighbor clubs; and } \\
\text { increased talent mass. }\end{array}$ \\
\hline
\end{tabular}

Handball North $\quad$ Club: Large Club. A full-time TDC, assistant
senior elite team coach. Also worked part time in the federation.

Federation: Strategy to support local ATDEs to increase the talent mass in the local clubs. One full time TDC.

Municipality: Strategy focused on sport classes and coordination between all 14 local handball clubs in the municipality. One full time employed TDC.

Formal agreements: Partnership contract contained financial conditions and general guidelines. Informally developed vision of collaboration.

Issues to solve: Athlete burnout due to lack of coordination between clubs and sport classes.

Handball East Club: Medium size. TDC is a full-time coach
and sport director.

Federation: Strategy to support local ATDE with a goal to increase talent mass. One full time TDC.

Municipality: Strategy to financially support initiatives on their mutual strategy. Two full time TDCs, which allowed for in-depth

collaboration.

Formal agreements: Partnership contract contained financial conditions and general
C- and F-TDC knew each other well. The M- and C-TDC worked in the same building and thus had ample opportunity to meet informally.

All collaborators met a few times per year (e.g., when selecting new handball pupils for sport classes), and the $\mathrm{C}$ - and M-TDC met daily. Together they arranged workshops with the F-TDC to educate all the coaches in the club and integrated handball training in the publicschool sport program.

Shared assumptions: Helping the minor local clubs is key to maintain talent mass; and coordination between school and clubs is vital to avoid training overload. Outcomes: Increased quality in school and club training; and decreasing injuries.

The TDCs knew each other well and thus had access for support and feedback. The Municipality had financial resources to support the collaboration initiatives. Quarterly meetings with all collaborators. On-going meetings between $\mathrm{C}$ - and M-TDC helped them to organize and execute their strategy initiatives. Together, they implemented whole season planning, recovery initiatives and a digital forum to communicate and coordinate.

Shared assumptions: Late specialization to maintain talent mass; and optimizing communication to integrate efforts. 


\begin{tabular}{|c|c|c|}
\hline & $\begin{array}{l}\text { guidelines. Informally developed vision of } \\
\text { collaboration. } \\
\text { Issues to solve: Dropout and small talent } \\
\text { mass. Only two senior elite players from the } \\
\text { local club. }\end{array}$ & $\begin{array}{l}\text { Outcomes: Improved training program for the players, } \\
\text { which has resulted in fewer injuries and dropouts. }\end{array}$ \\
\hline Handball West & $\begin{array}{l}\text { Club: Medium size. Part-time TDC. } \\
\text { Federation: Strategy to support local ATDEs } \\
\text { with a goal to educate the club coaches. } \\
\text { Municipality: Strategy to educate the club } \\
\text { coaches and support the club financially based } \\
\text { on the coaches' educational level. TDC is former } \\
\text { elite handball player. } \\
\text { Formal agreements: Partnership contract } \\
\text { contained financial conditions and general } \\
\text { guidelines. Informally developed vision of } \\
\text { collaboration. } \\
\text { Issues to solve: No strategy for TD in the } \\
\text { club. No local players on the elite team. }\end{array}$ & $\begin{array}{l}\text { The TDCs knew each other well and had handball } \\
\text { backgrounds. The F-TDC was part-time employed in the } \\
\text { club and thus had significant impact on the club's } \\
\text { initiatives. } \\
\text { Together they held ongoing meetings and workshops to } \\
\text { educate the coaches within the ATDE and in the nearby } \\
\text { clubs. Raised funds to employ a part time C-TDC and } \\
\text { implemented meetings with players about well-being } \\
\text { and development. } \\
\text { Shared assumptions: High quality in training is key to } \\
\text { maintain talent mass; whole ATDE is vital for the } \\
\text { athletes' development. } \\
\text { Outcomes: Improved quality of the coaches within the } \\
\text { ATDE; developing a joint strategy for TD in the ATDE. }\end{array}$ \\
\hline Handball North-west & $\begin{array}{l}\text { Club: Large club. Full-time TDC. } \\
\text { Federation: Strategy to support local ATDE by } \\
\text { increasing the talent mass in the local club. } \\
\text { Municipality: Strategy to increase the talent } \\
\text { mass in the sport classes and support the ATDE } \\
\text { through sport class initiatives. } \\
\text { Formal agreements: Partnership contract } \\
\text { contained financial conditions and general } \\
\text { guidelines. Informally developed vision of } \\
\text { collaboration. } \\
\text { Issues to solve: The school sport classes } \\
\text { lacked handball pupils due to poor collaboration } \\
\text { with minor local clubs who were afraid to lose } \\
\text { their players. }\end{array}$ & $\begin{array}{l}\text { TDCs are full-time employees. M- and C-TDC worked in } \\
\text { short distance and had easy access to meet. } \\
\text { C- and M-TDC communicated and met daily. Mutually; } \\
\text { they arranged inspirational training workshops for the } \\
\text { ATDE and neighboring clubs' coaches. They substituted } \\
\text { the word "talent" in their program to "motivated for } \\
\text { sport" and developed a gradual progression in training } \\
\text { load. } \\
\text { Shared assumptions: Include as many athletes as } \\
\text { possible; late specialization to maintain talent mass; } \\
\text { and a whole person approach to TD. } \\
\text { Outcomes: Better collaboration with neighboring clubs; } \\
\text { and an efficient support program in sport classes. }\end{array}$ \\
\hline Ice Hockey North & $\begin{array}{l}\text { Club: Large club. Part-time TDC. } \\
\text { Federation: Strategy to help local ATDE's by } \\
\text { emphasizing dual career and growing the } \\
\text { number athletes. } \\
\text { Municipality: Strategy to build collaboration } \\
\text { between school and sport and attract new } \\
\text { players. } \\
\text { Formal agreements: Partnership contract } \\
\text { functioning as a declaration of intent containing } \\
\text { a shared vision and action plan. } \\
\text { Issues to solve: Small talent mass in the } \\
\text { ATDE and balancing dual career. }\end{array}$ & $\begin{array}{l}\text { C-TDC was part time employed in both the club, } \\
\text { municipality and federation, and thus has easy access } \\
\text { to the other TDCs. They could decide on their priority of } \\
\text { resources and time allocation. } \\
\text { C- and M-TDC met daily and helped the ATDE to nurture } \\
\text { initiatives into action. They implemented ice hockey in } \\
\text { the local schools to attract ice hockey players to the } \\
\text { club. } \\
\text { Shared assumptions: Include as many as possible; dual } \\
\text { career is central to a socially responsible TD approach. } \\
\text { Outcomes: Increased talent mass in the club; finances } \\
\text { to employ local coaches; and dual-career balance. }\end{array}$ \\
\hline Ice Hockey mid & $\begin{array}{l}\text { Club: Medium sized. Full-time TDC. } \\
\text { Federation: Strategy to help local ATDE's by } \\
\text { emphasizing dual career and growing the } \\
\text { number of athletes. } \\
\text { Municipality: Strategy to develop collaboration } \\
\text { between the local sport clubs and to } \\
\text { disseminate research knowledge about TD to } \\
\text { the club. } \\
\text { Formal agreements: Partnership contract } \\
\text { functioning as a declaration of intent containing } \\
\text { a shared vision and action plan. } \\
\text { Issues to solve: Lack of quality in training and } \\
\text { players that burn out due to too many matches. }\end{array}$ & $\begin{array}{l}\text { The collaborators knew each other well for more than } \\
10 \text { years. The C-TDC and M-TDC had easy access to } \\
\text { meet. All collaborators could decide on their priority and } \\
\text { time allocation. } \\
\text { C- and M-TDC communicated and met daily which } \\
\text { facilitated knowledge sharing. Initiatives to decrease the } \\
\text { number of matches per season and planned training } \\
\text { weekends with focus on quality training and social } \\
\text { arrangements. } \\
\text { Shared assumptions: Include as many as possible; dual } \\
\text { career is important; and TD is about developing senior } \\
\text { elite athletes. } \\
\text { Outcomes: Increased talent mass in club and school } \\
\text { sport classes; strengthened preconditions for high } \\
\text { quality training. }\end{array}$ \\
\hline
\end{tabular}

Table 1: Snapshot description of the cases included in the cross-case analysis 
three overall themes containing six shared features (or subthemes) was produced and structured into the list of Shared Features of Interorganizational Collaboration in Talent Development (from here: the SFIC-TD list; see Table 2). Fifth, to aid practitioners, and in a heuristic approach based on our own experiences of working with ATDEs, we further structured the shared features into an applied framework termed the Pyramid Model for Optimization of Interorganizational Collaboration in Talent Development (PIC-TD) (see Figure 2). Sixth, the first author arranged workshops, meetings, and member reflections (Smith \& McGannon, 2017) with TDCs intending to ensure that our findings accurately represented the participants' perspectives as well as increase natural and transferable generalizability (Smith, 2018). Seventh, after feedback from the TDCs, the authors finalized the SFIC-TD list and the PIC-TD model and presented the results as shown below. To ensure rigor (Smith \& McGannon, 2017), we prioritized critical reflections within the research group throughout the data analysis process and approval from the study participants. Searching for consensus between different opinions was a key to finalize the two major outcomes of this study.

\section{Findings}

This multiple case study focused on 11 case examples of successful collaborations between clubs, municipalities, and sports federations within Denmark. In the context of real life, the cases all differed in terms of club size, sport type, collaboration history, and available resources. Further, each collaboration was distinctive in the way it was bounded through personal relationships, uniquely rooted in local municipalities each presenting different opportunities and challenges, as well as how each collaboration contributed to the development of the local ATDE. However, taken collectively, we found a number of shared features that distinguish how successful collaborations are organized, maintained, and executed. Below we describe the shared features of successful IC in talent development, summarized in the SFIC-TD list (Table 2) and then organize them into the PIC-TD model (Figure 2).

\section{Collaborative Phillosophy}

Successful collaborations in this study did not exist without the sharing of essential values and ideas of talent development (i.e., talent development happens in the local club, talent development is a long-term effort), and the data overwhelmingly demonstrated that all collaborations were rooted in these shared assumptions. Noticeably, these assumptions varied across the cases, but the most important point was that they were mutually shared within the collaboration. Still, two features of collaborative philosophy were essential.

Shared Understanding of The Talent Development Processes and Factors Involved

This feature highlighted the importance of shared understanding of what talent is and what is vital in the talent development processes. In Denmark, guidelines developed by Danish sporting organizations (e.g., Team Denmark and Danish Sport Confederation) played a major role, as discussed by a Club-TDC from Handball NorthWest: "When we disagree on initiatives or are in doubt about where to focus, most often we can find specific recommendations in the guidelines from Team Denmark and solve the issues." Further, there were agreements upon the importance of high quality in daily training and in the day-to-day activities within the local ATDE, as explained by Municipality-TDC working with Ice Hockey North and Swim North:
'The youth national team swimmers do not progress significantly during a national team event. After all, it is what happens day to day, year to year, that is crucial for their long-term development, and the quality of what goes on in the daily training is the club's responsibility. That is why the local club is so important for an athlete. The club needs to make sure that the coaches are skilled, the athletes are improving, and that everyone thrives. These are all factors that we know well are crucial to good development.

The overall idea that talent development is a complex affair without a one-size-fits-all solution seemed to be agreed upon across cases and served as a foundation for the collaborators to discuss important matters (e.g., What is talent? What is efficient talent development?). When stakeholders shared assumptions about talent development, it facilitated the process of developing and implementing a mutual talent development strategy.

Shared Long-term Vision and Aim to Enhance the Local ATDE

As discussed earlier, the Danish sport system works from a decentralized talent development strategy, prioritizing the role of the local clubs in the talent development process. All three federations had a vision to enhance the local ATDEs and consequently all collaborations were created for this specific purpose. The Municipality-TDC that worked with both Ice Hockey Mid and Handball Mid mentioned, "I am sure that both the handball and ice hockey clubs are informed that we collaborate to craft the best possible local talent development environments within the existing possibilities."

In every case there was a mutual understanding that talent development was about developing senior elite athletes in a socially responsible manner and developing a mutual long-term vision of the collaboration was in fact a partnership criterion listed by the federation. The swimming Federation-TDC gave an example from the case of Swim-West: "The partnership contract was not signed until we shared a long-term vision. The club went through a talent development strategy seminar [facilitated by the municipality] to develop a common understanding of where to go, how, and why."

The same idea was present in the handball and ice hockey federations, where historically they had supported clubs with resources based on the clubs' performance, but now the support was distributed depending on their longterm strategy. The Handball North Club-TDC expressed it, "What I really liked about collaborating with the FederationTDC is that he worked research-based and emphasized long-term efforts (...) today we select players not on their performance, but rather on their potential [to learn and develop further]."

The federations have previously been criticized for preaching long-term efforts while simultaneously emphasizing the importance of youth national team results and organizing championships for kids under the age of 13 . Now the visible long-term focus of the federations in their guidelines has rubber-stamped selecting for potential rather than "here and now" performance.

Collaborative Decisions

In each case, the stakeholders emphasized the importance of collectively generating and sharing knowledge and ideas as well as making decisions in conjunction with other collaborators, rather than unilaterally. Working this way was due to a shift in the federation's approach to collaborate on local talent development. Several TDCs highlighted that the federations changed from being a "controller" of the local club monitoring their performance to become a "collaborator" trying to understand the contextual needs of the club and develop a common 
strategy from the club's perspective. The federations' new approach was central to ensure empowerment of all the stakeholders as expressed by the handball Federation-TDC: 'Although we have highly skilled coaches and TDCs within the federation, we must acknowledge that the most important influence is not what happens in athletes' interaction with the federation but in the club. It is vital that we establish a close dialogue with the club stakeholders. Meaningful Relationships

The participants described meaningful relationships as relationships created and maintained to work together on the issues professionally and personally meaningful for the collaborators. The ice hockey Federation-TDC has noted:

'We say that we are like a small family. We know one another both professionally and personally and I feel that we have strong relationship, which makes it easy to come to the clubs and give a helping hand. Of course, most families have that annoying brother or sister, so we do not always agree with everyone, but we remain respectful at all times.

With only 12 ice hockey clubs in Denmark the relationships between the clubs and the federation was quite close. In handball and swimming, there are more clubs with different types of relationships in their collaborations. Some were professional, some informal and friendly and most were somewhere in between described as a "professional relationship with a friendly spirit."

Open Communication and Knowledge Sharing

Associated with meaningful relationships, the collaborators also emphasized the importance of having open communication and knowledge sharing, and in each case a stakeholder, such as the Municipality-TDC at Swim-South, would stress the importance of open communication in this relational context, "It is really important to have an open communication to be able to challenge each other's assumptions and ideas. To share concerns openly we need trust".

Each stakeholder represented their own organization with individual visions and strategies, but open communication helped to foster trust between the collaborators and to make sure to unite their efforts into a mutual collaborative strategy despite their differences. However, the stakeholders emphasized that it took time for openness to grow and that ongoing communication was key in that process. In all the cases they told about how they met formally at least 3-4 times a year and had ongoing informal communication by e-mails or phone. The Club-TDC from Handball North-West said, "The ongoing communication helps to keep the collaboration on track and is important to ensure motivation for the initiatives."

\section{Collaborative Actions}

A shared feature of the successful partnerships was that what was decided in boardrooms turned into action. Plans were realized and not stalled between the partners. From the 11 cases, our analysis highlighted two shared features. Collective Work on Current and Future Tasks

The collaborations were not about political branding or symbolic efforts to showcase cross-disciplinary partnerships. Instead, they solved specific issues together that influenced the everyday life in the ATDE as exemplified in Swim North by the Club-TDC:

'The swimmers often arrive late from high school to training and it stresses them a lot. So, I contacted the Municipality-TDC and as usual it did not take long before we arranged a meeting with the sports coordinator at the high school, had a cup of coffee, and found a common solution. In this case, it was decided that the swimmers could leave school 15 minutes early.

In extension, in Ice hockey Mid the athletes suffered from a heavy loaded match schedule and very little time for quality practice during a regular week. The Club-TDC took action with support from the Municipality-TDC as explained by the latter:

'The Club-TDC told me recently that the club actually refused to participate in a youth tournament. Instead, they held a training camp for the whole club, practiced ice hockey, played football and did a social arrangement in the evening. The Club-TDC asked me to approve the initiative, which I did.

The fact that the Municipality-TDC was asked to okay the club's decision illustrates how they matched expectations of each other's role and mandate, which underpins the importance of the next shared feature.

Clearly Defined Roles and Functions

Sometimes the stakeholders explained a meaning of successful collaboration by telling stories from other less successful collaborations. For example, they could all tell about how they have experienced (in the past or in other collaboration alliances) wasting time being involved in several meetings and never knowing their own and the others' roles and functions when executing plans. Therefore, they highlighted the importance of clarifying roles and functions within the collaboration and even though they differed slightly between collaboration cases, the Municipality-TDC collaborating with Handball Club West defined each stakeholder's role in a representative way:

'The role of the handball federation is to provide sport specific expert knowledge and help the local ATDE to spot untapped potentials. The municipality's function is to facilitate and expand the scope of the collaboration by, for example, connecting local sport clubs, sport and school, and to provide access to local government funds. The club's role is to share insights in needs and issues of the club with the collaborators and hereafter to implement initiatives of the collaboration. The club must take ownership to execute the strategy, and in the end, it is the most essential element of the collaboration.

The functions and expectations could vary depending on the local ATDE's issue, but they all emphasized the importance of developing transparent expectations of who is responsible for what, and that the club should be able to implement the strategy.

\section{Organizing the Shared Features into an Applied} Framework

As mentioned at the beginning of the findings, the discovered features of IC were organized in two ways. First, the findings are summarized in the SFIC-TD list (Table 2), which is a depiction of the six shared features of the ICs and includes the descriptors of the features and their opposite poles to further clarify the meaning of each. For example, the feature shared long-term vision and aim to enhance the local ATDE is described as an agreement that significant positive changes in the local ATDE can be achieved only with long-term vision, plans, and collaboration, whereas the opposite pole describes collaborators focusing only on short-term goals and outcomes. Second, the same shared features complemented by the collaboration outcomes were organized into the PIC-TD applied model (Figure 2) with the intention to optimize IC in athletic talent development. The PIC-TD model organizes the shared features as a pyramid and the idea is that each lower layer provides the ground for the level above it. The foundational level of the PIC-TD model (seen as a basis for successful IC) is a. Collaborative philosophy that embraces these two features: understanding the talent development process and factors. involved, and shared long-term vision and aim to enhance the local ATDE. 


\begin{tabular}{|c|c|c|}
\hline & Positive descriptors & Opposite pole descriptors \\
\hline \multicolumn{3}{|l|}{ Collaborative Philosophy } \\
\hline $\begin{array}{l}\text { Shared understanding of the } \\
\text { talent development } \\
\text { processes and factors } \\
\text { involved }\end{array}$ & $\begin{array}{l}\text { Basic assumptions about efficient } \\
\text { talent development are shared, and } \\
\text { the collaborators have a good } \\
\text { foundation to develop and implement } \\
\text { TD strategies. }\end{array}$ & $\begin{array}{l}\text { No agreements or shared vision on } \\
\text { the talent development processes. } \\
\text { Conflicts and tensions arise when } \\
\text { planning and implementing } \\
\text { strategies. }\end{array}$ \\
\hline $\begin{array}{l}\text { Shared long-term vision and } \\
\text { aim to enhance the local } \\
\text { ATDE }\end{array}$ & $\begin{array}{l}\text { Agreement between the collaborators } \\
\text { that they work to enhance the local } \\
\text { ATDE and that it can be achieved } \\
\text { only with long-term vision, plans, } \\
\text { and collaboration. }\end{array}$ & $\begin{array}{l}\text { Contradictory interests. } \\
\text { Collaborators are unclear about the } \\
\text { long-term goal of collaboration and } \\
\text { thus focus only on short-term goals } \\
\text { and outcomes. }\end{array}$ \\
\hline \multicolumn{3}{|l|}{ Collaborative Decisions } \\
\hline Meaningful relationships & $\begin{array}{l}\text { Collaborators trust each other, } \\
\text { establish both professional and } \\
\text { personal relationships facilitating } \\
\text { communication and decision making }\end{array}$ & $\begin{array}{l}\text { Misunderstandings are often, } \\
\text { relationship issues occur but ignored } \\
\text { or not solved effectively. }\end{array}$ \\
\hline $\begin{array}{l}\text { Open communication and } \\
\text { knowledge sharing }\end{array}$ & $\begin{array}{l}\text { Regular and ongoing communication } \\
\text { (e.g., meetings, phone calls and } \\
\text { emails); collaborators are free to } \\
\text { express ideas or concerns and come } \\
\text { up with suggestions. }\end{array}$ & $\begin{array}{l}\text { Meetings and communication are } \\
\text { irregular, and collaborators are } \\
\text { unwilling or uncomfortable to share } \\
\text { their ideas, concerns, or } \\
\text { suggestions. }\end{array}$ \\
\hline \multicolumn{3}{|l|}{ Collaborative Actions } \\
\hline $\begin{array}{l}\text { Collective work on current } \\
\text { and future tasks }\end{array}$ & $\begin{array}{l}\text { Meetings are purposeful, with an eye } \\
\text { on the future, and aimed to solve } \\
\text { concrete tasks within the local ATDE } \\
\text { (i.e., educating coaches, solving } \\
\text { facility issues, balancing dual career } \\
\text { etc.) }\end{array}$ & $\begin{array}{l}\text { Meetings lack intention to solve } \\
\text { specific current or future tasks. } \\
\text { Proposals are rather stay in the } \\
\text { meeting room than converted into } \\
\text { action enhancing the local ATDE. }\end{array}$ \\
\hline $\begin{array}{l}\text { Clearly defined roles and } \\
\text { functions }\end{array}$ & $\begin{array}{l}\text { The tasks of the actions are clear, } \\
\text { plans are made; roles and functions } \\
\text { are distributed among the } \\
\text { collaborators and executed with a } \\
\text { flexibility required by the } \\
\text { circumstances to reach the intended } \\
\text { outcomes. }\end{array}$ & $\begin{array}{l}\text { Collaborators' uncertainty about } \\
\text { their own and the others' roles and } \\
\text { functions in executing the plans } \\
\text { makes collaborative actions chaotic } \\
\text { and not leading the intended } \\
\text { outcomes. }\end{array}$ \\
\hline
\end{tabular}

Table 2: The Shared Features of Successful Interorganizational Collaboration in Talent Development (SFIC-TD)

At the next level, we find Collaborative decisions, underpinned by two features: meaningful relationships, and open communication and knowledge sharing. Collaborative actions are the third level and encompasses two shared features: collective work on current and future tasks, and clearly defined roles and functions. The top of the pyramid includes a fourth level portraying the interplay between the three levels leading to Collaborative outcomes, which enhance the local ATDE.

\section{Outcomes}

Outcomes of the IC were always evaluated by the stakeholders on improvements of the local club. However, improvements could take many shapes, such as an increased talent mass, improved facilities, strengthened educational level of the coaches, working closer to the federation's guidelines, and promoting dual career balance. An example of a successful outcome was highlighted by Handball East's Club-TDC that described how the club dealt with players' dropouts and overuse injuries, explaining they now are more proactive in their approach:

'Now, we plan a yearly training schedule for the upcoming under (age) 14 players by coordinating the training load of their morning practice in school and afternoon practice in the club. We make sure they get two times 32-hour recovery breaks a week. We also replaced some handball trainings with resistance training based on physical tests.
With these efforts, we see less overuse injuries in the youth teams. We could not have accomplished this without the Municipality-TDC who has been a central figure in communicating our aims to those parents who want their kids to just play handball and win games.

For each case of collaboration, it was emphasized that they collaborated to accomplish outcomes that none of the organizations could have accomplished on their own. The Municipality-TDC of Swim West said, "When we sit down together, the club, the federation, and the municipality, we agree completely on the strategy. We unite our human and financial resources and coordinate our efforts. And I really think that the club has a say."

\section{Discussion}

The aim of this study was to explore 11 case examples of successful talent development collaborations between sport federations, municipalities, and local clubs in Denmark in order to identify potential shared features of successful collaborations. We found six shared features (see the SFICTD in Table 2) that we organized into the PIC-TD applied model (see Figure 2). Below we elaborate how these two major study outcomes contribute to the HEA, to previous research, and to applied work. 


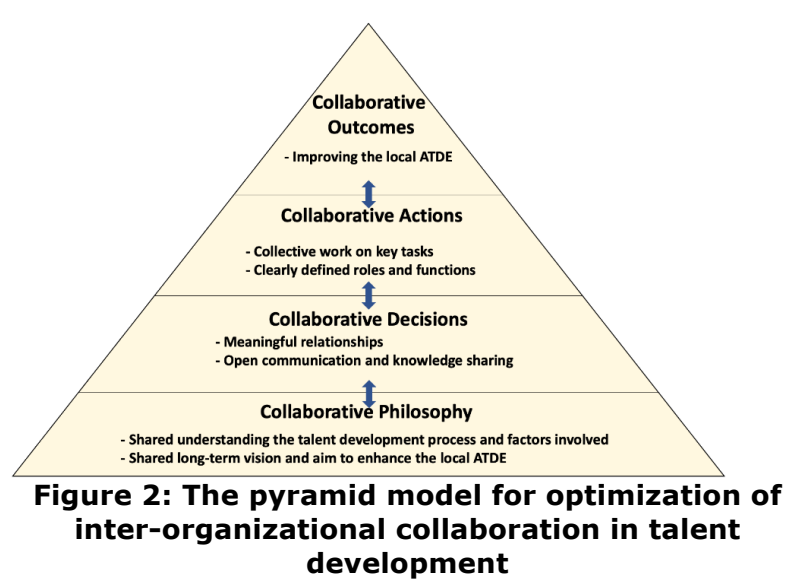

Conceptual Contribution to the Holistic Ecological Approach

The present study makes a conceptual contribution to talent development research. Over the last decade, a body of research has investigated ATDEs using the HEA (Henriksen \& Stambulova, 2017). These studies have provided a holistic presentation of ATDEs, however, at the expense of in-depth analyses of specific components and relationships within the environments (Mathorne et al., 2020). One such area that could benefit from detailed attention is the collaboration between stakeholders at the micro- and macro-level to promote local talent development. A recent study using the HEA (Mathorne et al., 2020) specifically focused on the collaboration between a federation, a municipality, and a local club. From this research, the authors developed the organizational triangle concept that points at collaborative relationships between key organizations within an ATDE.

In the present study, we explored 11 successful examples of talent development collaborations between sport federations, municipalities, and local clubs in Denmark. The shared features of these examples are summarized in the SFIC-TD (Table 2). Beyond serving as a summary, this table can inspire researchers in their future investigations of successful and less successful IC. Finally, and with practitioners in mind, we developed the PIC-TD model (Figure 2). This model organizes success-features of collaborations in a pyramid shape where some features provide the foundation for the next. Our intention is that this model will serve as a guide for practitioners working to optimize collaborations in their local talent development by providing a structure for interventions where some aspects should be addressed before others.

In this sense, the current study contributes to research from a holistic ecological approach by providing a lens for studying a specific part of the ATDE (i.e., interorganizational relationships), presenting a summary of successful cases, and by suggesting a model to guide interventions.

Collaborative Philosophy as a Foundational Starting Point

The results of this study showcase that shared features of successful collaboration in talent development exist, and mirror findings within sport management literature (Babiak $\&$ Willem, 2017). The feature of collaborative decisions (i.e., meaningful relationships, open communication) uncovered in this study reflects findings in other studies that emphasize features such as; open communication, regular interaction, engagement, and building trust between collaborators as vital (Babiak, 2007; Babiak \& Willem, 2017; Misener \& Doherty, 2012; Sotiriadou et al., 2017). Collaborative actions (i.e., collective work on current and future tasks, clearly defined roles and functions) have also been found to be an integral feature of collaboration including; pro-active problem-solving and clearly defined roles (Babiak \& Willem, 2017; Barnes et al., 2007; Misener \& Doherty, 2012; Sotiriadou et al., 2017). However, the collaborative philosophy as a shared feature of successful collaboration in talent development is a novel contribution to IC literature. Studies within sport management literature discuss that additional challenges can arise when collaborators do not share values and missions, but these studies primarily focus upon broader macro level issues such as sponsorships, media, and governing bodies (Babiak \& Willem, 2017). We found for the 11 successful cases of collaboration in local talent development that an agreed upon and shared philosophy was a necessary foundation for success. A shared philosophy of talent development is crucial because it serves as a strong foundation for decision-making and action. This was the case in the example of Swim West, where the Federation-TDC emphasized the importance of a mutual understanding of where to go, how, and why, within the collaboration.

\section{Applied Perspectives}

Building upon previous research (Babiak \& Willem, 2017; Misener \& Doherty, 2012), collaborative competencies (e.g., interpersonal understanding, teamwork, cooperation, etc.) of the collaborators are vital for the success of IC. The present study supports this notion and we suggest that organizations (i.e., federations, municipalities, clubs) working in the field of talent development in sport should incorporate collaborative competencies as a vital criterion when recruiting TDCs as well as ensuring the new TDC shares the organization's philosophy of talent development. Being explicit and clear about the organization's philosophy can aid in the recruitment of personnel who value and maintain established ICs. A person's philosophy of talent development can evolve (Henriksen, 2015; Junggren et al., 2018; Storm, 2020), but we propose that recruiting people who share established philosophical assumptions can facilitate smoother integration of new employees.

For sport psychology practitioners (SPPs) to be able to assist ATDEs (and not only individual athletes), we support a call for curricula in the education of SPPs to include a stronger emphasis on how to work on the organizational (Wagstaff, 2019) and interorganizational level (Mathorne et al., 2020). With this education, future SPPs may play a role in assisting organizations (e.g., federations, municipalities) in developing the efficient structures (e.g., sufficient time, flexibility and decisionmaking power for TDCs) and shared philosophy that will allow ICs to avoid deadlocks and to flourish (Babiak \& Willem, 2017).

As mentioned above, the PIC-TD model (Figure 2) was developed as an applied contribution. The PIC-TD model might aid to guide and structure interventions to optimize existing collaborations or forming organizational triangles and helping them to build the collaboration effectively. For instance, the PIC-TD emphasizes the importance of investing time and effort in developing a collaborative philosophy rather than rushing to solutions and problem solving. Further, we emphasize that developing a collaboration is not a linear and fully predictable process, and the arrows within the PIC-TD model illustrate this back and forth collaboration dynamics. The SFIC-TD list complements the PIC-TD model by providing descriptors of the positive and opposite poles of the features helping SPPs to explain (in more detail) the meaning of each feature to the relevant stakeholders. 
Given the contextualized nature of any specific environment, we understand that the findings from a scientific study must first be considered, weighted, and measured before being applied into practice. The specific findings of the present study are likely mainly relevant in decentralized system where talent development takes places locally, and in contexts where talent development is valued above talent identification (often in smaller countries). However, we also believe in the applicability of our findings via transferable and naturalistic generalizability (Smith, 2018), both of which encourage the readers to consider the findings in the context of their own environments.

\section{Future Research}

This multiple case study of 11 successful collaborations presented challenges and opportunities given the uniqueness of the cases (e.g., relationship between the stakeholders, resources available in the collaboration, contextualized issues to solve). As IC is a new topic in talent development, we adopted an explorative approach and asked experts to identify successful case examples. The list of shared features identified in this study and the PIC-TD model can further be examined, challenged, and strengthened in studying ICs within ATDEs in different sporting and sociocultural contexts.

Investigating three federations created opportunities to truly capture the depth and breadth of a particular collaboration and to decipher details but also shared features across cases. For example, the Federation-TDC in handball was able to reflect upon and compare the collaboration in five unique cases, and this participant's insights were helpful in the identification of shared features of successful collaboration. This study's findings on successful ICs allowed us to only hypothetically suggest characteristics of less successful collaborations in talent development by formulating descriptions of the opposite poles within the SFIC-TD list. Investigating less successful collaborations in the future would help to further support or potentially alter the SFIC-TD.

To expand our knowledge about local talent development we suggest that researchers consider other organizational triangles (e.g., club-school-municipality) and investigate how different organizational triangles might complement the collaboration between club, municipality, and federation. We encourage researchers to investigate how successful local talent development in a real-life is underpinned by collaborations between micro- and macrolevels. To further expand our applied knowledge within the field of IC processes, we encourage future explorative intervention projects (i.e., participatory action research projects). Interventions could take many shapes as informed by local needs and structures, but would focus on collaborators working strategically with the processes inspired by the PIC-TD model. Such research could contribute to understanding the dynamic and complex nature of IC in talent development and add valuable insights into contextualized interventions.

After all, as the CEO of Team Denmark emphasized in the opening of this paper, world-class talent development is crucial for the success of elite sports, and municipalities, federations, and clubs are the key players in co-creating optimal local sport environments.

\section{References}

Andersen, S. S., Bjørndal, C. T., and Ronglan, L. T. (2015). The ecology of talent development in the Nordic elite sport model. In S. Andersen, B. Houlihan, \& L. T. Ronglan (Eds.), Managing Elite Sport Systems (pp. 49-66). Routledge.

Babiak, K. (2007). Determinants of interorganizational relationships: The case of a Canadian nonprofit sport organization, Journal of Sport Management, 21(3), 338-376. doi: 10.1123/jsm.21.3.338

Babiak, K., \& Thibault, L. (2009). Challenges in multiple cross-sector partnerships. Nonprofit and Voluntary Sector Quarterly, 38(1), 117143. doi: $10.1177 / 0899764008316054$

Babiak, K., Thibault, L., \& Willem, A. (2018). Mapping research on interorganizational relationships in sport management: Current landscape and future research prospects. Journal of Sport Management, 32(3), 272-294. doi:10.1123/jsm.2017-0099

Babiak, K. \& Willem, A. (2017). Interorganizational relationships in sport: From theory to practice. In R. Hoye \& M. Parent. The SAGE handbook of sport management (pp. 273-292). SAGE Publications Ltd. doi:10.4135/9781473957961.n16

Barnes, M., Cousens, L. and MacLean, J. (2007). 'From silos to synergies: A network perspective of the Canadian sport system'. International. Journal of. Sport Management and Marketing, 2(5/6), 555-571.

Bjørndal, C. T., Ronglan, L. T., \& Andersen, S. S. (2017). Talent development as an ecology of games: A case study of Norwegian handball. Sport, Education and Society, 22(7), 864-877. doi:10.1080/13573322.2015.1087398

Braun, V., \& Clarke, V. (2019). Reflecting on reflexive thematic analysis. Qualitative Research in Sport, Exercise and Health, 11(4), 589-597. doi:10.1080/2159676X.2019.1628806

Bronfenbrenner, U. (1979). The ecology of human development. Cambridge: Harvard University Press.

Hansen, L. (2018, November 15). Dansk talentarbejde skal være i verdensklasse [Danish talent development work must be worldclass]. Retrieved June 22, 2020, from

Retrieved June 22, 2020, from https://teamdanmark.dk/nyheder/2018/nove

Frisby, W., Thibault, L., \& Kikulis, L. (2004). The organizational dynamics of under-managed partnerships in leisure service departments. Leisure Studies, 23(2), 109-126. doi:10.1080/0261436042000224482

Henriksen, K. (2015). Developing a high performance culture: A sport psychology intervention from an ecological perspective in elite orienteering. Journal of Sport Psychology in Action, 6, 14-153.

Henriksen, K., \& Stambulova, N. (2017). Creating optimal environments for talent development: A holistic ecological approach. In J. Baker, S. Cobley, J. Schorer, \& N. Wattie (Eds.), Routledge handbook of talent identification and development in sport. Routledge, 2017, p. 271-284. doi: $10.4324 / 9781315668017$

Henriksen, K., Stambulova, N., \& Roessler, K. K. (2010a). Holistic approach to athletic talent development environments: A successful sailing milieu. Psychology of Sport and Exercise, 11, 212-222. doi:10.1016/j.psychsport.2009.10.005

Henriksen, K., Stambulova, N., \& Roessler, K. K. (2010b). Successful talent development in track and field: Considering the role of environment. Scandinavian Journal of Medicine \& Science in Sports, 20, 122-132. doi: $10.1111 /$ j.1600-0838.2010.01187.x

Junggren, S. J., Elbæk, L., \& Stambulova, N. (2018). Examining coaching practices and philosophy through the lens of organizational culture in a Danish high-performance swimming environment. International Journal of Sport Science and Coaching, 13(6), 1108-1119. doi:10.1177/1747954118796914

Mathorne, O., \& Henriksen, K. (2019). Lokal talentudvikling i samspil [Local talent development in collaboration]. Retrieved April 13, 2021 from: https://www.sdu.dk/-

/media/files/om_sdu/institutter/iob/forskningsenheder/lets/ole+samsp il+rapporter_net.pdf

Mathorne, O., Henriksen, K., \& Stambulova, N. (2020). An "Organizational triangle" to coordinate talent development: A case study in Danish swimming. Case Studies in Sport and Exercise Psychology, 4, 11-20. doi:10.1123/cssep.2019-0017

Miles, M., Huberman, A. and Saldaña, J. (2014). Qualitative data analysis. A methods sourcebook (3rd ed.). Thousand Oaks, CA: Sage Publications.

Misener, K., \& Doherty, A. (2013). Understanding capacity through the processes and outcomes of interorganizational relationships in nonprofit community sport organizations. Sport Management Review, 16(2), 135-147. doi:10.1016/j.smr.2012.07.003

Pankhurst, A., \& Collins, D. (2013). Talent identification and development: The need for coherence between research, system, and process. Quest, 65(1), 83-97. doi:10.1080/00336297.2012.727374

Parent, M. M., \& Harvey, J. (2009). Towards a management model for sport and physical activity community-based partnerships. European Sport Management Quarterly, 9(1), 23-45. doi: $10.1080 / 16184740802461694$

Schein, E. (1992). Organizational culture and leadership. San Francisco: Jossey-Bass.

Skrubbeltrang, L. S., Karen, D., Nielsen, J. C., \& Olesen, J. S. (2020). Reproduction and opportunity: A study of dual career, aspirations and elite sports in Danish sports classes. International Review for the Sociology of Sport, 55(1), 38-59. doi:10.1177/1012690218789037 
Smith, B. (2016). Narrative analysis in sport and exercise: How can it be done? In B. Smith, \& A. C. Sparkes (Eds.), Routledge handbook of done? In $B$. Smith, $\&$ A. C. Sparkes (Eds.), Routledge handbook of
qualitative research in sport and exercise (pp. 282-295). Routledge.

Smith, B. (2018). Generalizability in qualitative research: Misunderstandings, opportunities and recommendations for the sport and exercise sciences. Qualitative Research in Sport, Exercise and Health, 10(1) 137-149. doi:10.1080/2159676X.2017.1393221

Smith, B., \& McGannon, K. R. (2017). Developing rigor in qualitative research: Problems and opportunities within sport and exercise psychology. International Review of Sport and Exercise Psychology, psychology. International Review of Sport and Exercis

Sotiriadou, P., Brouwers, J., De Bosscher, V., \& Cuskelly, G. (2017). The role of interorganizational relationships on elite athlete development processes. Journal of Sport Management, 31, 61-79. doi: 10.1123/jsm.2016-0101

Stake, R.E. (2005). Multiple case study analysis. Guilford Publications.

Storm, L.K. (2020). Creating a successful talent development culture:

Context-driven sport psychology practice in a Danish talent academy.
Case Studies in Sport and Exercise Psychology, 4(1), 58-66. doi: $10.1123 /$ cssep.2019-0034

Storm, R. K., \& Nielsen, K. (2020). Danske eliteresultater 2019: Flere medaljer men færre medaljeaspiranter. Hvor godt er Danmark rustet til OL i Tokyo? [Danish elite sport results: More medals but fewer medal aspirants. How well is Denmark prepared for the Olympics in Tokyo?]. Idrættens Analyseinstitut.

Storm, R. K., Nielsen, K., \& Thomsen, F. (2016). Can a small nation be competitive in the global sporting arms race? the case of Denmark. Managing Sport and Leisure, 21(4), 181-202. doi:10.1080/23750472.2016.1243993

Team Denmark (2016). ATK 2.0 træning af børn og unge [general guidelines for age-specific training principles]. Brøndby: Team Denmark.

Wagstaff, C. R. D. (2019). A commentary and reflections on the field of organizational sport psychology. Journal of Applied Sport Psychology, 31,134-146. doi:10.1080/10413200.2018.1539885 